\title{
Epicardial pacing wires, a five year, single centre experience
}

\author{
J Abbas ${ }^{1 *}$, K Toombs $^{2}$, A Zaidi $^{2}$, JA Hoschtitzky ${ }^{2}$ \\ From 23rd World Congress of the World Society of Cardio-Thoracic Surgeons \\ Split, Croatia. 12-15 September 2013
}

\section{Background}

Indications for epicardial pacemaker insertion in the adult population include; complex congenital cardiac defects, difficult venous access, tricuspid valve pathology and in patients undergoing concomitant cardiac surgical procedures. It still remains unclear as to the best type of lead used for this.

\section{Methods}

Between February 2008 and October 2012, 103 epicardial pacing wires were implanted in 70 adult patients. Of these leads, 46 were included in the study. Information regarding the perioperative period and follow-up was analysed to determine the patient's clinical course and the durability of the pacing wires.

\section{Results}

On implantation the mean threshold of all the leads was $1.1+/-0.8 \mathrm{~V}$ at a mean pulse width of $0.5+/-0.7 \mathrm{~ms}$. The mean impedance of the leads was $673.4+/-268.1 \mathrm{OH}$. There was no difference in the implant data between unipolar and bipolar or steroid eluting and non-steroid eluting leads. There was a significantly lower pacing threshold in the steroid eluting leads at latest follow up $(\mathrm{p}=0.031)$. Similarly the pacing thresholds were lower in the bipolar leads when compared to the unipolar leads $(p=0.026)$. There was no difference in impedance.

\section{Conclusion}

Overall the epicardial pacing leads demonstrate satisfactory pacing thresholds and impedance trends in the follow-up time of this study. Bipolar leads were more durable than unipolar leads and leads which eluted steroid were favourable than those which didn't.

* Correspondence: jonathan.abbas@doctors.org.uk

${ }^{1}$ Salford Royal NHS Foundation Trust, Salford, UK

Full list of author information is available at the end of the article

\section{Authors' details}

'Salford Royal NHS Foundation Trust, Salford, UK. ${ }^{2}$ Manchester Heart Center, Central Manchester Foundation Trust, Manchester, UK.

Published: 11 September 2013

doi:10.1186/1749-8090-8-S1-089

Cite this article as: Abbas et al:: Epicardial pacing wires, a five year, single centre experience. Journal of Cardiothoracic Surgery 2013 8(Suppl 1):089.
Submit your next manuscript to BioMed Central and take full advantage of:

- Convenient online submission

- Thorough peer review

- No space constraints or color figure charges

- Immediate publication on acceptance

- Inclusion in PubMed, CAS, Scopus and Google Scholar

- Research which is freely available for redistribution
() Biomed Central 